\title{
MASSIVE PULMONARY EMBOLISM OCCURRING DURING ANAESTHESIA: REPORT OF THREE CASES
}

\author{
M. MrNuCK, M.D. ${ }^{\circ}$
}

THE PRESENTATION of these cases has been prompted by the recent appearance in this Journal of an article on "Massive Pulmonary Embolism during Anaesthesia."1 It was felt that the addition of three more cases to the literature would be interesting since few such reports may be found, in spite of the fact that pulmonary embolism is one of the commonest acute chest conditions occurring in hospital patients. Natof and Sadove in their book Cardiovascular Collapse in the Operating Room ${ }^{2}$ refer to " 49 episodes of pulmonary emboli or pulmonary aspiration" that had occurred during the induction of anaesthesia, but do not mention diagnosis or treatment. Drs. Browne and Catton indicate the difficulties in diagnosing the catastrophe should it occur during anaesthesia, and they point out our dependence on clinical signs. Attempts to diagnose massive pulmonary embolism under these conditions are further complicated since the use of controlled ventilation precludes the onset of a potentially valuable warning sign, i.e., rapid shallow breathing followed by apnoea.

During the past number of years I have collected three instances of death during anaesthesia caused by massive pulmonary embolism. In each case the cause of death was proved by post-mortem examination. These cases are presented together, since it seemed that the occurrence of the pulmonary embolism in each case was followed by a somewhat similar pattern of signs. It is hoped that knowledge of this pattern, coupled with a high index of suspicion, may help to bring some of these patients to a successful surgical (or medical) embolectomy.

Case 1

Age 66 (female), admitted August 5 with a diagnosis of carotid artery thrombosis. This patient had been investigated in another hospital and was transferred to St. Boniface General Hospital for surgical treatment under hypothermia. On August 10 the patient was brought to the operating room after receiving $25 \mathrm{mg}$. chlorpromazine, $25 \mathrm{mg}$. promazine and $50 \mathrm{mg}$. meperidine. Blood pressure was $110 / 80$ and pulse 80 . At 8:10 anaesthesia was induced with $350 \mathrm{mg}$. thiopentone and $5 \mathrm{mg}$. dimethyl d-tubocurarine. This was followed after preoxygenation, by intubation with a $\# 9$ cuffed endotracheal tube. The patient became deeply cyanosed, and in spite of unrestricted ventilation with 100 per cent oxygen, the colour did not improve. Ten minutes later it was still possible to obtain a good peripheral pulse but it was difficult to obtain the blood pressure. The pulse soon disappeared and all efforts at resuscitation were abandoned soon after. The post-mortem showed the presence of a massive pulmonary embolus in the main pulmonary trunk, extending into both the right and left main branches.

'Head, Department of Anaesthesia, St. Boniface General Hospital, St. Boniface, Manitoba; Assistant Professor, Department of Anaesthesia, University of Manitoba. 
Case 2

Age 61 (male), admitted January 10 with a diagnosis of carcinoma of the stomach and thrombosis of the left common iliac vein. After a period of investigation and preparation the patient was slated for ligation of his left common iliac vein under spinal anaesthesia. Premedication consisted of $75 \mathrm{mg}$. meperidine and $0.6 \mathrm{mg}$. atropine. A subarachnoid block was accomplished at $8: 10$ with $8 \mathrm{mg}$. pontocaine. The initial blood pressure was $120 / 80$, pulse 68 ; this was unchanged following the completion of the anaesthetic procedure. The operation was started at 8:35 but, since analgesia was inadequate, general anaesthesia was induced with $125 \mathrm{mg}$. pentothal and cyclopropane by mask, and the patient was intubated following paralysis with $60 \mathrm{mg}$. of gallamine. At 8:50, shortly after surgery was commenced, while the lower end of the inferior vena cava was being mobilized, the patient's condition suddenly deteriorated. The patient became cyanosed, and the blood pressure was unobtainable, although the radial pulse could still be readily felt. This soon disappeared, and although a carotid pulse could be felt briefly following an intravenous injection of methoxamine, there was never any improvement in colour, and all efforts were abandoned at 9:20. Post-mortem revealed the presence of a large embolus in the pulmonary artery.

Case 3

Age 76 (female), admitted September 2 with a diagnosis of hemiplegia due to a carotid artery thrombosis. After a period of investigation and treatment the patient was considered to be a candidate for surgical endarterectomy. Accordingly, on September 24, 22 days after admission, she was slated for surgery. She was premedicated with $60 \mathrm{mg}$. codeine and $0.9 \mathrm{mg}$. atropine. Initial blood pressure was $160 / 100$ and pulse $76 / \mathrm{min}$. The patient was given $100 \mathrm{mg}$. thiopentone and $60 \mathrm{mg}$. succinylcholine. The pharynx was sprayed with lidocaine 4 per cent and she was intubated with a \#10 cuffed endotracheal tube. The blood pressure was now $140 / 100$, the pulse $76 / \mathrm{min}$. and regular. Within seconds it was noted that the patient's colour was ashen. Blood pressure and pulse were unobtainable. Direct cardiac compression was begun; palpation of the main pulmonary trunk did not confirm the presence of a clot. All this was done within two minutes. There was no sustained cardiac response, and resuscitation was abandoned after twenty minutes. Post-mortem revealed the presence of a massive pulmonary embolism with some evidence of pulmonary artery thrombosis, indicating that the disease process may have begun preoperatively.

\section{Drscussion}

The oft-quoted sign of bronchospasm or prolonged expiration was absent in every case. The charateristic initial sign in each of the three cases described was the abrupt onset of deep cyanosis or ashen grey discoloration of the skin. This was unrelieved, in spite of unrestricted ventilation of both lungs (confirmed by the stethoscope) with 100 per cent oxygen. The blood pressure and/or pulse disappeared only after an interval (except in Case 3). 
All three patients had been confined to bed for varying periods prior to surgery. Patients 1 and 3 were confined to bed on account of hemiplegia and hemiparesis from carotid artery insufficiency, and patient 2 was confined to bed owing to weakness and inanition.

\section{SUMMARY}

Three cases of massive pulmonary embolus during anaesthesia have been presented. This catastrophe occurred in patients whose preoperative course of bed confinement had set the stage for the possible development of a pulmonary embolus. Two patients developed signs immediately following induction of anaesthesia and one during manipulation of the common iliac vein. An abrupt development of deep cyanosis, unrelieved by ready ventilation of all lung fields with 100 per cent oxygen, in a patient who might be a candidate for pulmonary embolus should evoke the thought of this possibility. The persistence of a palpable peripheral pulse eliminates a primary diagnosis of sudden heart arrest. Steps should be taken to make a swift diagnosis so that definitive treatment may be considered. Finally, these cases emphasize, as Jacoby et al. ${ }^{3}$ have pointed out, the importance of not accepting responsibility for a death associated with anaesthesia without a thorough post-mortem examination.

\section{RÉSUMÉ}

On présente trois cas d'embolie pulmonaire massive durant l'anesthésie. Cette catastrophe est survenue chez des malades qu'un alitement pré-opératoire prolongé avait prédisposés à cette complication. Deux malades ont présenté des symptômes immédiatement après l'induction et l'autre durant les manipulations de la veine iliaque primitive. L'apparition d'une cyanose importante, non diminuée par la ventilation immédiate à 100 pour cent d'oxygène de toute la surface pulmonaire, chez un malade prédisposé à l'embolie pulmonaire devrait faire penser à cette pathologie. La persistance du pouls périphérique élimine le diagnostic d'arrêt cardiaque. On doit s'appliquer à faire un diagnostic rapide et précis afin d'étudier la possibilité d'un traitement adéquat. Enfin ces cas soulignent comme l'ont fait remarquer Jacoby et collaborateurs, l'importance de pratiquer une autopsie complète avant d'accepter la responsabilité d'une mort imputable à l'anesthésie.

\section{REFERENCES}

1. Browne, R. A. \& Catron, D. V. Massive Pulmonary Embolism during Anaesthesia: A Report of Two Cases. Canad. Anaesth. Soc. J. 14: 413 (1967).

2. NatoF, H. E. \& Sadove, M. S. Cardiovascular Collapse in the Operating Room. Lippincott (1958).

3. Jacoby, J.; Lutskx, I. I.; Henschel, E. O.; \& Green, R. E. Fatalities Erroneously Attributed to Anesthesia. Anesth. \& Analg. 44: 53 (1965). 